\title{
Why a folder lies in the basket although it is not lying: the semantics and use of German positional verbs with inanimate Figures ${ }^{1}$
}

\author{
SILVIA KUTSCHER AND EVA SCHULTZE-BERNDT
}

\section{Abstract}

In this paper we will investigate the meaning and use of positional verbs in colloquial Standard German. Positional verbs are defined as those verbs which may appear in the basic construction that functions as an answer to a "where"-question, the so-called Basic Locative Construction (BLC). Within this class of verbs, we focus on those positionals which are used to describe the configuration of inanimate movable objects. We will demonstrate that German exhibits the characteristics of a positional (or "multiverb") language, i.e., a language that uses a comparatively large set of verbs in the BLC. The ten positionals used most frequently in our data are stehen 'stand', liegen 'lie', hängen 'hang', lehnen 'lean', stecken 'be in tight fit, be stuck', klemmen 'be stuck, be jammed', kleben 'stick by means of glue', haften 'adhere', schwimmen 'be afloat in liquid', and schweben 'be afloat'. We will identify the conditions under which the positional verbs are used and provide a semantic characterization for each of them, paying particular attention to alternative categorizations, fuzzy boundaries and prototype effects.

\section{Introduction}

In this paper, we examine the meaning and use of positional verbs that are used to describe the location of inanimate, movable objects in colloquial Standard German, in a construction identified as the Basic Locative Construction (BLC; see Section 2). In English, the main verb used in this context is the semantically general locative/copular verb be. In German, the corresponding verb sein 'be' is also found in the BLC. Its use is even obligatory in certain contexts, to be identified in Section 4 below. Wherever possible, though, speakers of the variety studied here - colloquial Standard German spoken in Germany - employ one of a core set of at 
least ten positional verbs (for an interesting study of rather dramatic differences between regional varieties of German in this respect see Berthele $2004 \mathrm{a}, \mathrm{b})$. The positionals that occur regularly in our data are stehen 'stand', liegen 'lie', hängen 'hang', lehnen 'lean', stecken 'be in tight fit, be stuck', klemmen 'be stuck, be jammed', kleben 'stick by means of glue' (with its more marginal alternative haften 'adhere'), schwimmen 'be afloat in liquid', and schweben 'be afloat'. We will demonstrate that German exhibits the characteristics of a "positional verb language" or multiverb language, in that the use of these positionals is determined by the perceived configuration of the Figure and the Ground. Consequently, any nominal whose referent can hold more than one configuration with respect to a Ground can occur with more than one of the positional verbs. We will identify the conditions under which each of the positional verbs is used, paying particular attention to alternative categorizations, fuzzy boundaries and prototype effects.

A substantial part of the data on which this paper is based were elicited with the Topological Relations Picture Series (TRPS) and the Picture Series for Positional Verbs (PSPV), stimuli designed specifically for this purpose at the MPI for Psycholinguistics, Nijmegen. These depict Figure-Ground configurations presented in random order. Each presentation of a picture of a Figure and a Ground (e.g., a bottle on a rock, PSPV 10) is accompanied by the question "Where is <Figure>". Although the first, spontaneous answer to this question was taken to be the most prominent for denoting the stimulus situation, the consultants were encouraged to discuss alternative expressions. When a consultant used an alternative expression it was checked whether the expression could also apply to comparable pictures in the stimuli series that had already been discussed. Thus, the average time to complete the whole series per language consultant and picture book (71 stimuli in the TRPS series and 68 in the PSPV series) was two hours. In order not to exhaust the consultant, the tasks were preferably done over several sessions. For comparability of the data, a number of at least three consultants had been recommended in the guidelines. For the TRPS tool we worked with four consultants, for the PSPV tool, with eight.

The picture book stimuli were supplemented by stimuli involving real objects which were designed - often ad hoc - by ourselves to explore aspects of positional use specific to German; in examples, these will be referred to as "Bochum Stimuli" since most of the interviews were conducted in Bochum. Here a less formal elicitation procedure was used and the number and type of stimuli used with the various consultants are not directly comparable; moreover, sometimes more than one consultant was present at the same time and contributed to the answer. Additional data 
come from overheard, spontaneous utterances, from the Cologne corpus of spoken German narratives (marked as "Kölnkorpus"), and from the electronic corpus of the Institut für deutsche Sprache (IDS) in Mannheim (URL: http://www.ids-mannheim.de/cosmas2). Examples for which no source is indicated have been constructed based on the native speaker competence of the two authors. As can be gathered from these remarks, the procedures described above were intended as an exploration of the semantic range and limits of applicability of the positional expressions in question rather than as a psycholinguistic experiment allowing for a statistical account of the use of positional verbs in German. Nevertheless, we sometimes give frequency indications if we feel that these point to interesting tendencies deserving further systematic investigation.

The paper is organized as follows. In Section 2 we introduce the basic locative construction in German and distinguish it from several formally or functionally related constructions. In Section 3 we discuss the meaning of each of the positional verbs listed above, i.e., those used with inanimate Figures in the basic locative construction. In Section 4, we examine the conditions under which the locative/copular verb sein 'be', rather than one of the more specific positional verbs, is used. The results are summarized in Section 5.

\section{The Basic Locative Construction and alternatives}

\subsection{The Basic Locative Construction}

The German Basic Locative Construction (BLC), i.e., the construction that is employed in answers to 'where' questions like wo ist <Figure> 'where is $<$ Figure $>$ ', ${ }^{2}$ consists of a subject noun phrase in the nominative representing the Figure, a locative verb, a prepositional phrase, where the NP represents the Ground and is in dative case indicating static location, ${ }^{3}$ and, optionally, a locative adverb. The BLC is schematically represented in (1) and illustrated in (2). ${ }^{4}$

(1) $\left[\mathrm{NP}: \mathrm{NOM}_{\text {Figure }}\right] \mathrm{V}_{\text {Locative }}\left[\mathrm{P}_{\text {Top.Rel. }}\left[\mathrm{NP}: \mathrm{DAT}_{\text {Ground }}\right]\right] \mathrm{Adv}_{\text {Top.Rel. }}$

(2) a. Die Kirschen sind in einer Schale drin the cherries be:3PL.PRS in a bowl inside 'The cherries are in a bowl'

b. Die Bücher liegen auf der Erde the books lie:3PL:PRS on the ground 'The books are (lit. 'are lying') on the ground' (Bochum Stimuli) 
c. Deine Jacke hängt am Haken
POSS:2SG coat hang:3SG:PRS on:the hook
'Your coat is (lit. 'hangs') on the hook'
(Bochum Stimuli)

As the examples in (2) show, the locative verb as well as the preposition (and possibly the optional adverb) vary according to the configuration and topological relationship between the Figure and the Ground. For example, in (2a), the verb sein 'be' encodes a nonspecific locative relationship and the preposition in encodes a topological relation of containment. ${ }^{5}$ In (2b), the positional verb liegen 'lie' encodes a horizontal configuration of the books (a characterization to be refined in Section 3.3 below), and the preposition auf encodes a relationship of support from below. The verb hängen 'hang' in (2c) is used to indicate that the Figure is supported, but not from below, i.e., its configuration is partly determined by gravity (see further Section 3.4), and the preposition an 'at' encodes a nonspecific attachment of the Figure to the Ground. In this paper, we will only be concerned with the contribution of the locative verb to the interpretation of expressions of this type, although, as we will see throughout Section 3, there is a certain interdependence between the choice of a positional verb and the topological relation encoded by the preposition or adverb. As Gerling and Orthen (1979: 69) point out, however, the PP chosen as the Ground does not necessarily correspond to the supporting entity, i.e., the entity that is in contact with the Figure, but can also represent a Ground in the vicinity of the Figure, or a container. This observation is supported by our data; see e.g., example (37).

The Basic Locative Construction may be extended by a secondary predicate which provides more specific information about the configuration between Figure and Ground than the positional verb alone. The secondary predicate can be an underived predicative adjective, an adverb such as quer 'diagonally' (see [28]), or a past participle form of a verb functioning as a deverbal adjective, such as umgekehrt 'upside down' (see [27]) or verstreut 'scattered' (see [33]). This additional predicate tends to be employed if the configuration is nonstereotypical, in accordance with the Manner principle (cf. Levinson 2000) which states that a marked state of affairs requires a more marked expression.

Conversely, in a spontaneous question-answer dialogue, the Figure NP as well as the verbal predicate can be omitted, and the position of the Figure can be expressed via the Ground PP (the focused constituent) only. This abbreviated expression tends to be used only if the configuration is stereotypical, like that described in (3); this is again consistent with the Manner principle. 

(3) Q: Wo ist die Kaffeetasse? where be:3SG:PRS the coffee.cup
A: Auf dem Tisch on the table

Q: 'Where is the (coffee) cup?' - A: 'On the table' (Bochum Stimuli, cf. TRPS 1)

If a verb is present in an answer to a 'where' question, the use of a stative locative verb, as in examples (2a)-(2c) above is the most typical. However, dynamic verbs may also be used with the same type of Ground PP, as is illustrated in (4) and (5).

Wo ist $\quad$ Peter? - Der arbeitet im
where be:3SG:PRS Peter DEM
Garten
garden

'Where is Peter?' - 'He is working in the garden'

Wo ist $\quad$ die Fahne? - Die Fahne flattert
where be:3SG:PRS the flag the flag flutters:3SG:PRS
am Mast

'The flag flutters on the mast'

(TRPS 56)

Expressions like those in (4) and (5) convey an additional specification of a state of affairs which goes beyond the purely locative information. The construction employed here can also be distinguished from the BLC on formal Grounds, because with a nonlocative verb, the Ground PP can be omitted (although the resulting expression would not be quite felicitous as an answer to a 'where' question). With a locative verb, on the other hand, the Ground PP is (near) obligatory. It can only be omitted if the verb is accented under contrastive focus (as indicated by capitals in the following and other examples), e.g., if the location is known and the actual configuration of the Figure is at stake, as in (6) (see also [35] in Section 3.3).

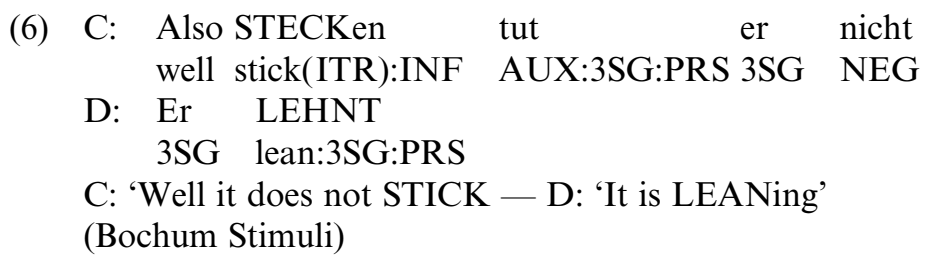

Since expressions like that in (6) are also not good answers to a 'where' question, the construction with contrastive focus is distinguished here 
from the BLC. In the latter, the verb is unstressed and the nominal in the $\mathrm{PP}$ is stressed.

The syntactic status of the obligatory Ground PP has been frequently discussed in the literature. An analysis is made more difficult by a certain gradability of obligatoriness (see the detailed discussion in Maienborn 1990, 1991). For some locative verbs, the Ground PP is claimed to be optional, as e.g., in (7). ${ }^{6}$

Rita liegt (auf dem Bett)
Rita lie:3SG:PRS on the bed
'Rita is lying (on the bed)'
(Maienborn 1991: 52)

However, this (marginal) optionality of the Ground PP only seems to hold for animate Figures with human posture verbs. Even contextual reconstruction of the locative expression does not work for positional verbs with inanimate Figures, as shown in (8).

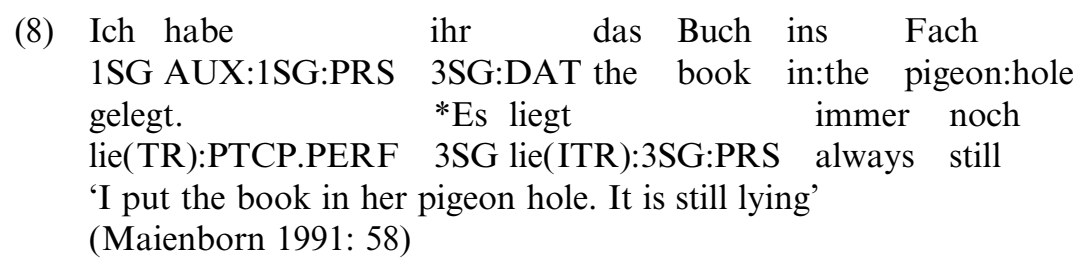

Various analyses of the Ground PP have been suggested, which partly reflect the theoretical stance of the authors. What all authors seem to agree upon is the status of the Ground PP as a semantic/conceptual argument of the locative verb, and we will follow this analysis here. The presence of a near-obligatory Ground PP defines the set of stative locative verbs in German. In Section 3, we will define positional verbs as a subset of these locative verbs on semantic grounds.

Finally, German has a number of verbs with locative semantics that take part in constructions distinct from the BLC, although they can also be employed in answers to a 'where' question. The first type are active verbs construed with an accusative NP representing the Ground, e.g., bedecken 'cover', säumen 'line, skirt, border'. The second type are verbs which take a directional and not a stative locative Ground PP. These can be either reflexive verbs such as sich schmiegen 'cling to', sich spannen 'stretch across' or nonreflexives such as ragen 'project, protrude from' (cf. Kaufmann 1995: 113-115). Except for the last verb, they hardly occurred in our data, and will not be further considered here. 


\subsection{Constructions related to the Basic Locative Construction}

There are two constructions in German that correspond to the BLC in that they consist of basically the same constituents, including a locative verb, and only deviate from the BLC in word order. The first of these is the Ground-oriented locative construction, illustrated in (9), which is formally almost identical to the BLC, except that the Ground PP is in sentence-initial position. The consequence of this change in word order is that, unlike in the BLC, the Ground PP functions as topic of the utterance.

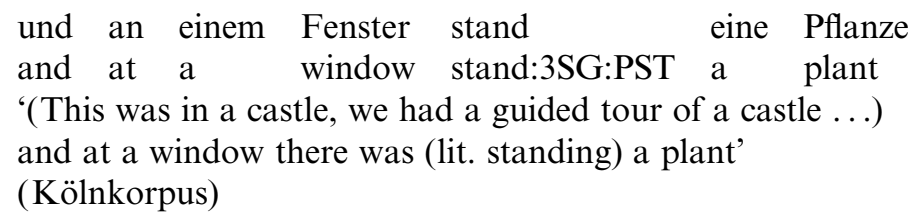

The second construction related to the BLC is the presentational $d a$ construction. The presentational construction contains an initial locative pronoun $d a$ 'there', followed by a locative verb, the subject NP, and a locative PP expressing the Ground, as shown in (10). Da-constructions are thetic utterances, i.e., they present all-new information. ${ }^{7}$

(10) (...) denn da hängt eine Jacke am
because there hang:3SG.PRS a coat on:the
Haken
hook
'(I don't know where she is but I think she has already
arrived) because there is a coat on the hook' (overheard
utterance)

This construction can also be used to form negative presentational clauses, by replacing the indefinite article with the negative indefinite article kein (see [11]). In negative statements of this type, positional verbs may be used if the configuration of the Figure and Ground is a stereotypical, expected one; otherwise, the locative/copular verb sein 'be' tends to be used (see Section 4.1).

$\begin{array}{lllll}\text { (11) (..) } & \text { denn da hängt } \\ \text { because there hang:3SG:PRS no } & \text { Jacke am } \\ \text { Haken } \\ \text { hook }\end{array}$

'(She is certainly gone,) because there is no coat on the hook' 
Both the Ground-oriented locative constructions and the presentational $d a$-construction differ from the BLC in that the Figure is not topical, but rather part of the focus of the utterance. Correspondingly, the subject NP expressing the Figure is usually indefinite. Therefore, both constructions cannot be used in answers to a 'where' question, but are rather used to introduce new topics into a discourse. Although the choice of positional verb in these constructions seems to be conditioned by the same factors as the choice of verb in the BLC, for the purpose of this study we will restrict ourselves to those positional verbs found in the BLC in our data.

\subsection{The 'full of' construction}

A further construction which is specific to (a subset of) locative verbs is the 'full of' construction, which is used to describe a configuration where a Ground is more or less completely filled or covered with multiple instances of the same type of Figure. The Ground is encoded as the subject, and the Figure is encoded in an adjectival phrase involving voll 'full' (variants are voller 'full of', voll von 'full of', and voll mit 'full with'). If the verb functioning as the predicate is the semantically neutral stative verb sein 'be', the resulting expression corresponds to its English translation equivalent, as in the example in (12).

(...) da war die ganze Wand nur noch voller
then be:3SG:PST the whole wall only still full.of
Zettel
notes
'(...) then the whole wall was full of notes'
(Kölnkorpus)

In German (and Dutch; cf. Lemmens 2002: 123f.), unlike in English, however, some positional verbs may also function as the predicate in this construction. The resulting expressions are semantically deviant in that the positional appropriate of the Figure is used even though the subject is the Ground (this is somewhat reminiscent of the English swarm alternation, cf. Levin 1993: 53-55). Presumably because of this marked argument linking, not all positional verbs are acceptable as the predicate in this construction. Because of its rarity, we do not have spontaneous data employing this construction; the examples in (13) are taken from the IDS corpus.
Der Apfelbaum hing voller Früchte the apple.tree hang:3SG:PST full.of fruits 'The apple tree was full of fruits' (lit. 'was hanging full of fruits') (IDS M02/208.62596) 
(14) Die Strassengräben lägen voll Unrat. the ditches lie:3PL:SUBJUNCT full.of rubbish 'The ditches supposedly are full of rubbish' (lit. 'are lying full of rubbish')

(IDS R98/MÄR.19702)

Preliminary investigations revealed a considerable variation in the acceptability of individual verbs in this construction, but suggest that the more basic positional verbs liegen 'lie', stehen 'stand', hängen 'hang' and stecken 'be stuck, be in tight fit' are much more readily accepted than the semantically more specific verbs lehnen 'lean', kleben 'stick by means of glue', klemmen 'be stuck, be jammed', schweben 'be afloat', and schwimmen 'be afloat in liquid'. Moreover, the construction seems to be more acceptable with inanimate than with animate Figures.

\subsection{The Result construction (Zustandspassiv)}

Another construction that is functionally, but not formally related to the BLC is the result construction, called Zustandspassiv (lit. "passive of state') in German traditional grammar writing. It consists of the verb sein 'be' and the perfect participle of a dynamic verb. This construction, which depicts a state - in this case, the configuration between the Figure and the Ground - as the result of a dynamic event, is employed relatively frequently in the descriptions elicited with our stimuli. For example, it accounts for roughly $10 \%$ of the spontaneous responses to the PSPV tool. Sometimes it is the only possible way to describe a certain configuration; for example, there is no positional in German that would allow one to describe the configuration of a string (or another flexible two-dimensional object) wound around an object serving as the Ground. Expressions such as (15) were therefore regularly used to describe the corresponding stimulus.

Das Band ist um den Stein
the ribbon AUX:3SG:PRS around the stone
gewickelt
wind:PTCP.PERF
'The ribbon is wound around a stone'
(PSPV 15)

In other cases, the result construction was used as a spontaneous alternative to the BLC, by different speakers or by even the same speaker, to describe the same configuration. An example is (16). 
(16)

a. Die zwei Stöcke stecken in der Erde

The two sticks stick(ITR):3PL:PRS in the ground 'The two sticks "are stuck" in the ground' (PSPV 9)

b. Die Stöcke sind in den Boden

The sticks AUX:3PL:PRS in the ground gerammt ram:PCTP.PERF

'The sticks are rammed into the ground' (PSPV 9)

The verbs used in the result construction form an open class; since they are dynamic, they clearly cannot be considered as positionals. They will therefore not be further considered in this study.

\section{Semantics of the positional verbs}

In the previous section, we have defined the Basic Locative Construction (BLC) as the most basic construction that is ordinarily used in answers to a 'where' question and only conveys the location of an entity. In colloquial Standard German, the BLC consists of a nominative NP representing the Figure, a locative verb, an obligatory (or at least near-obligatory) PP where the preposition encodes the topological relationship between Figure and Ground and the NP represents the Ground, and optionally, a locative adverb. Positional verbs are a subset of the locative verbs found in this construction. The locative verbs also include the semantically general locative/copular verb sein 'be' since with this verb, too, the Ground PP is obligatory. We therefore do not consider expressions containing this verb as instantiating a different construction from the BLC, despite the fact that, like its English equivalent, sein 'be' has additional functions as a copular verb. The locative verbs found in the BLC - i.e., those demanding a Ground PP, except where the verb is in contrastive focus form a rather large set. In this section, we will define a subset of these as positional verbs on semantic grounds, and discuss their meaning in some detail.

\subsection{Positionals vs. other stative locative verbs}

Positional verbs in German do not constitute a formally definable class. They do not belong to a separate conjugation class, nor do they show 
any other specific morphosyntactic patterns that distinguish them from other stative locative verbs. In the literature on German positional verbs one can find two ways of subclassification. The first is in accordance with traditional German grammar writing and subsumes the positionals under the large group of stative verbs (Zustandsverben), with the defining criterion of relating entities to a location (cf. Gerling and Orthen 1979: 63). In contrast, authors in the generative grammar tradition, represented e.g., by Maienborn (1990, 1991) and Kaufmann (1995), regard these verbs as a subgroup of a larger class of locative verbs, containing verbs of position (e.g., stehen 'stand', liegen 'lie'), verbs of motion (e.g., gehen 'walk', humpeln 'limp') and of caused location (e.g., stellen 'put', legen 'lay'). What both approaches agree upon is that stative locative verbs can be defined as the semantic subclass of stative verbs encoding a relation between entities serving as a Figure and a location. As already shown in Section 2.1, this also has a formal correlate, the obligatoriness of a PP representing a location.

A large subset of stative locative verbs are in general restricted to animate Figures and include such verbs as sitzen 'sit', 8 knien 'kneel', hocken 'crouch', and kauern 'squat'. All these verbs make reference to a body part which is in contact with a supporting surface, and/or a particular posture or gestalt-like configuration of an animate entity. The use of some verbs of this group marginally extends to inanimates as well, for example, sitzen 'sit, perch', illustrated in (17) (see also Fagan 1991: 142) or thronen 'be enthroned, sit in majesty'. The verb balancieren 'balance' was used by some speakers to describe stimuli such as 26 in the TRPS stimuli, depicting a bottle on a rock in a somewhat unstable position.
(17) Der Hut? Ist
aufm, sitzt
aufm Kopf
the hat be:3SG:PRS on:the sit:3SG:PRS on:the head 'The hat? Is on the, sits on the head'

(TRPS 5)

Verbs from another subset are restricted to human figures. They denote the location in a place of residence (e.g., wohnen 'live in a house', zelten 'stay in a tent') or a temporary residence (e.g., pausieren 'have a break', rasten 'take a rest', nächtigen 'spend the night') rather than referring to the position of the Figure with respect to the Ground. There is a special verb denoting residency of animals - nisten 'nest' - that can neither be extended to humans nor to inanimates. The verb wachsen 'grow' has a stative reading in describing the location of a plant.

Verbs such as ruhen 'rest' und lagern 'be in store' can also be used for inanimate Figures, as is illustrated in (18) and (19). These verbs denote 
the persistence of the location rather than a specific position or orientation of the Figure.
Die Weinflaschen lagern im Keller the wine.bottles be.stored:3PL:PRS in:the basement 'The wine bottles are stored in the basement'

Die Brücke ruht auf mehreren Pfeilern
the bridge rest:3SG:PRS on several pillars
'The bridge rests/is supported on several pillars'
(Wahrig)

Verbs restricted to animate Figures, and verbs with semantic components other than those pertaining to the spatial configuration of a Figure and a Ground, will be excluded from consideration here. The remaining stative locative verbs that can be used with inanimate Figures and occur in the BLC will be referred to as 'positional verbs'.

In the literature dealing specifically with the semantics of German positionals one can mainly find attempts of a formal representation of the meaning of the verbs, either in terms of componential analysis (Coseriu 1968; Kotschi 1974; Gerling and Orthen 1979), or in terms of a semantic primitives approach (Wunderlich and Kaufmann 1990; Maienborn 1990; Kaufmann 1995). These tend to work with idealized data and leave out of consideration variation and prototype effects in the description of particular, nonconventional configurations. Other analyses are restricted to only a subset of the verbs (Fagan 1991; Serra Borneto 1996).

In the remainder of this section we discuss the meaning of each of those positional verbs which are regularly used in our data to describe the position of inanimate movable Figures in the Basic Locative Construction. We will demonstrate that many configurations allow for multiple categorizations, or show prototype effects. We will also consider the effect of containment, which is often ignored in the literature but has been shown to be the crucial feature determining the use of the Dutch verb zitten 'sit' with inanimate Figures (Lemmens 2002).

The positional verbs in our corpus of spoken data correspond to those considered by Kaufmann (1995: 120). Following her subdivision, we assume a major subgrouping according to the nature of the supporting entity. Two specific positionals are used if the supporting entity is a liquid (schwimmen 'be afloat in liquid') or a gas (schweben 'be afloat'9). The majority of positional verbs require a solid supporting Ground; these can be further subdivided into verbs specifying the type of contact (kleben 'stick by means of glue', haften 'adhere', stecken 'be in tight fit, be stuck', klemmen 'be stuck, be jammed') and verbs specifying a type of support 
acting against gravity, where the support may be from below (stehen 'stand', liegen 'lie') or not from below (hängen 'hang'). Stehen and liegen are distinguished by the presence of a base, and the orientation of the maximal axis with respect to the Ground. A summary of the semantics of the positionals described in this paper is provided in Figure 1 in Section 5. A more precise characterization of the meaning of each of the verbs will be provided below. The semantically general verb sein 'be', which is nonspecific as to the configuration between Figure and Ground, is interchangeable with each of the positional verbs in principle, but in many contexts, the use of a more specific positional verb is preferred over sein 'be'. The conditions under which the use of sein 'be' is preferred or even required will be discussed in Section 4.

As outlined in Section 2.1, all positional verbs require a prepositional phrase representing a Ground (unless the verb is in contrastive focus), and semantically entail the presence of a supporting entity. With respect to their other formal properties, the members of this semantically defined group of positionals are rather nonhomogenous. Some inflect regularly (i.e., are so called schwache Verben 'weak verbs'); these are lehnen 'lean', kleben 'stick by means of glue', haften 'adhere', stecken 'be in tight fit, be stuck', klemmen 'be stuck, be jammed', and schweben 'be afloat'. The positionals stehen 'stand', liegen 'lie', hängen 'hang', and schwimmen 'be afloat in liquid', on the other hand, are so called starke Verben 'strong verbs' which show ablaut in the past tense and past participle forms.

With the exception of schweben 'be afloat' and schwimmen 'be afloat in liquid', all of the verbs just listed have transitive counterparts with the meaning 'place into Ving position', where $\mathrm{V}$ is the intransitive verb. They also vary concerning the form of those counterparts. The transitive counterparts of liegen 'lie' and stehen 'stand' are the partially suppletive forms legen and stellen; for the other verbs the same form can be used intransitively and transitively, although the transitive hängen 'hang' follows the regular ('weak') conjugation, while, as just indicated, intransitive hängen is a strongly inflected verb with a past tense form hing. These transitive verbs are often discussed together with the intransitive verbs in the literature (cf. Gerling and Orthen 1979; Fagan 1991), but, because of the restriction of this paper to positional verbs, they will be left out of consideration here (where they show up in examples they are marked as 'TR' in the glosses). The configuration between a Figure and Ground is the same for the intransitive and transitive verb of a pair, in other words, the conditions of use of the transitive verbs can usually be derived from the conditions of use of their intransitive counterparts which are described here. 


\subsection{Stehen 'stand'}

The verb stehen 'stand' (along with liegen 'lie') is one of the most frequent positional verbs both with animate and inanimate Figures. Like liegen 'lie', stehen also has extended and metaphorical uses, which are left out of consideration here (see Serra Borneto 1996). ${ }^{10}$

With animate Figures, stehen is the verb used to describe the - typical - configuration where the Figure is supported from below, and is in contact with the Ground with its feet/legs (cf. the dictionary definition sich auf den Füßen halten 'remain on one's feet' in Wahrig). With inanimates, as has been pointed out by Serra Borneto (1996: 463), stehen is generally used for Figures which have a "base", defined as a "clearly distinguishable section of their shape (...) through which the contact between the object and the support is realized." The base can resemble the legs/feet of animates, as in the case of pieces of furniture such as tables, beds etc. or the wheels of vehicles, but it can also be defined in functional terms. In this case, the base is the surface on which an entity is canonically deposited, e.g., the bottom of a container. Especially in the latter case, an additional criterion is that the entity "must have a certain amount of rigidity" and "be able to support itself" (Fagan 1991: 138). For example, a carpet has a surface on which it is canonically deposited, but its canonical position can only be described with liegen, not with stehen.

The presence of a base in the relevant rigid Figures - a cup, a video recorder, and a folding chair - triggers the use of stehen in examples (20) to (22) from our data.

(20) Die Tasse steht aufm Tisch the cup stand:3SG:PRS on:the table 'The cup is (lit. 'is standing') on the table' (TRPS 1)

(21) Q: Und der Videorekorder, wo ist der? and the video.recorder where be:3SG:PRS DEM
A: Der steht im Schrank

DEM stand:3SG:PRS in:the cupboard

Q: 'And the video recorder, where is it?' - A: 'It is (lit. 'is standing') in the cupboard' (Bochum Stimuli)

(22) Der Liegestuhl (..) steht auf dem Balkon the folding.chair stand:3SG:PRS on the balcony 'The folding chair is (lit. 'is standing') on the balcony' (Bochum Stimuli) 
The use of stehen can also be triggered metonymically. For example, in (23) it is not, strictly speaking, the referent of the subject noun phrase (butter) which is the Figure, but the container in which it is conventionally kept (a plate or butter dish), which has a conventionally assigned base (cf. also Fagan 1991: 138; Serra Borneto 1996: 463). If the piece of butter was wrapped in paper only, the configuration of a piece of butter on a fridge would be described with liegen 'lie', since the Figure here lacks a distinguishable base.

Die Butter steht auf dem Kühlschrank
the butter stand:3SG:PRS on the fridge
'The butter is (lit. 'is standing') on the fridge'
(overheard utterance)

In the case of Figures lacking a distinguishable base, stehen can only be used if the Figure has a greater extension in the vertical dimension than in the other dimensions, i.e., if it is "upright" (cf. Wahrig's dictionary definition and Serra Borneto 1996). This may be regarded as a schematization of the upright posture of humans on their feet. The relevance of the verticality schema as an additional criterion on which the use of stehen can be based is illustrated in examples (24) to (26). The Figures in these examples - sticks, a book, and a spoon - do not have a base, but have one saliently extended axis. If this axis is aligned horizontally with the supporting Ground, the verb liegen is regularly used with all these Figures (compare examples [28] to [30] in Section 3.3). If this dimension extends vertically, stehen is used.

(24) Die Stöcke stehn im Boden

the sticks stand:3PL:PRS in:the ground

'The sticks are (standing) in the ground'

(PSPV 9)

(25) Das Buch steht im Regal

the book stand:3SG:PRS in:the shelf

'The books are (standing) on the shelf'

(TRPS 8)

$\begin{array}{lll}\text { Q: Wo } & \text { ist } & \text { der Löffel } \\ \text { where } & \text { be:3SG:PRS } & \text { the spoon }\end{array}$

A: Der steht in der Tasse

DEM stand:3SG:PRS in the cup

Q: 'Where is the spoon' - A: 'It is (standing) in the cup'

(Bochum Stimuli)

The criterion of verticality also holds for the categorization of the configuration of a box (Schachtel), although Fagan (1991: 140) claims that the 
noun Schachtel generally occurs with liegen 'lie'. In our data, liegen was not accepted for a box with a salient vertical axis - e.g., a box holding $10 \mathrm{CDs}$ - and stehen was used instead.

That the component of verticality is secondary compared with the component of "base" is shown by the categorization of Figures which in their canonical position have little or no vertical extension but a distinguishable base, such as beds or plates. The verb stehen is infallibly used to describe the canonical position of such objects. As soon as they are in noncanonical position, however, liegen has to be used instead, e.g., to describe a plate which is upside down. In this case, thus, the presence or absence of vertical extension triggers the use of stehen vs. liegen. With objects which are vertically extended although in a noncanonical position, stehen is generally used (usually modified by a secondary predicate), although there is some variation in the judgment of speakers. Thus, 7 out of 8 speakers used stehen for the configuration depicted in PSPV 12 (a vase-shaped clay pot upside down on a tree trunk), i.e., they gave responses similar to (28). However, one speaker used liegen, and one used first liegen, then stehen, and judged both as acceptable. Other stimuli showing an object which was vertically oriented but upside down elicited similar patterns.

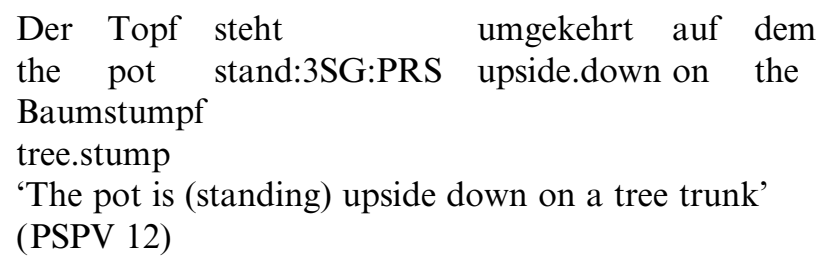

Not only a noncanonical orientation, but also a noncanonical Ground can be responsible for the use of liegen rather than stehen, although the judgment is even less clear in these cases. For example, in order to complement the data elicited with the PSPV tool, we tested the configuration of a plate placed on top of a cup. The 5 consultants participating in this test disagreed on the appropriate positional to describe this situation: 3 out of 5 speakers used stehen (and, when asked, justified this with the canonical orientation of the plate) and the other two used liegen (and claimed that stehen could not be used because the plate was not in its conventional position). Similarly, for a plate placed on the floor rather than a table, liegen is the verb used if the position of the plate is perceived as accidental, but stehen is used or accepted if it is construed as purposeful (as in the use of a plate to provide food for a pet dog or cat). Similar observations have been provided for the corresponding Dutch positionals by Lemmens (2002: 119-122). 
The effect of a noncanonical Ground also accounts for the variation in the responses to PSPV Stimuli 48 and 29. Both depict a pot on a thin branch in a tree, leaning slightly against the tree or another branch. Even where the pot has its canonical orientation (PSPV 48), only 5 out of 8 speakers used stehen (and not without further modification), and one explicitly rejected this verb. Where the pot is turned upside down (PSPV 29), the number of speakers using stehen is reduced to three (out of 8), with an additional two who considered it very marginally acceptable.

Containers often also count as noncanonical Grounds - especially in cases where a canonical position is unlikely to be maintained, notably in movable containers like baskets, as opposed to a cupboard. Thus, in our data, the verbs liegen 'lie' or sein 'be' tend to be used for objects in a container. For example, a plate in canonical orientation in a basket would be referred to with liegen, not with stehen. Even for the upright bottle in a rather large basket depicted in PSPV 62, one speaker (out of 8) used liegen and not stehen, although an upright bottle on a table would invariably elicit stehen. For PSPV 67, depicting a bottle upside down in a basket, 3 speakers used stehen (of which one immediately corrected herself and judged only sein as acceptable), 3 used liegen (of which one also accepted stehen), and 2 used lehnen 'lean' (see Section 3.5). The verb sein 'be' is the only choice if the container is flexible, e.g., a bag (see Sections 3.3 and 4.3). The variation in the choice of positional thus seems to depend on the perceived stability of the configuration. Moreover, for Figures inside a container the criterion of verticality seems to override the criterion of presence of a base in the choice of stehen.

\subsection{Liegen 'lie'}

The verbs stehen and liegen are in direct opposition since both positionals entail configurations of support from below only, and merely differ in the orientation of the Figure with respect to the supporting Ground. ${ }^{11}$ According to Serra Borneto (1996), liegen is used for inanimate Figures either when the most salient axis of the Figure is aligned horizontally with the Ground, or when the Figure lacks a salient dimension, i.e., is round or otherwise symmetrical or near symmetrical. This characterization is confirmed by our data.

In examples (28) to (30), the most salient dimension is aligned horizontally with the Ground. If it was aligned vertically, stehen would be used (compare the use of liegen vs. stehen in [29], and examples [24] to [26] in Section 3.2 above). 
(28) Der Stock liegt quer über dem Baumstumpf the stick lie:3SG:PRS diagonally across the tree.stump 'The stick is (lit. 'is lying') diagonally across the tree stump' (PSPV 61)

(29) Das [Buch] liegt auf den Büchern, die im the book lie:3SG:PRS on the books REL in:the Regal stehen shelf stand:3PL:PRS

'The (book) is (lit. 'is lying') on the books which are (lit. 'are standing') on the shelf'

(Bochum Stimuli)

(30) Meiner [Löffel] liegt auf der Untertasse POSS:1SG spoon lie:3SG:PRS on the saucer 'Mine (i.e., my spoon) is (lit. 'is lying') on the saucer' (Bochum Stimuli)

The verb liegen is also used for two-dimensional, flexible objects such as pieces of cloth or ropes, which may be extended or folded up, as long as they are supported from below. For objects of this type, because of their nonrigid nature, stehen is not usually an alternative configuration, although, as one speaker pointed out spontaneously, napkins can stehen (if folded up appropriately) as well as liegen. If a flexible object extends over the supporting Ground, the verb hängen (see Section 3.4) is also appropriate for this portion of the Figure. A configuration of this type in the PSPV Stimuli is typically described with a biclausal expression employing both verbs, as in (31). However, a table cloth in canonical position is usually just described with liegen.

Das Seil liegt
the rope lie:3SG:PRS across the basket and
hängt
hang:3SG:PRS an den Seiten runter
on the sides down

'The rope is (lit. 'is lying') across the basket and is hanging down on the sides'

(PSPV 63)

The Figures in examples (32) and (33) lack both a salient dimension and a canonical base. Here too, liegen is used, and stehen is not available as an alternative. This also holds for small multiple objects like beans.
Der Ball liegt
aufm Boden
the ball lie:3SG:PRS on:the ground
'The ball is (lit. 'is lying') on the ground'
(PSPV 7) 


\section{(33) Die Bohnen liegen verstreut aufm Boden the beans lie:3PL:PRS scattered on:the ground 'The beans are lying scattered on the ground'} (PSPV 11)

As also indicated in Sections 3.2 and 3.5, liegen serves as a residual positional for Figures in a rigid container which however does not contain the Figure in its canonical, stable position (as is the case e.g., for cupboards where the verbs stehen 'stand' and lehnen 'lean', which require a stable support relation, may be applied). In other words, liegen can be applied to a Figure in a container even if the longest axis of a Figure is not strictly speaking horizontally aligned, which is a necessary criterion for the use of liegen with asymmetrical Figures outside containers. This difference is sometimes explicitly commented on by speakers, as in (34) and (35). Example (34) was a response to a stimulus similar to PSPV 22 (a single bottle in a basket in a diagonal configuration), which the speaker judges not to be in a 'proper', i.e., prototypical, liegen configuration.

(34) Sie liegt in dem Korb, aber nicht richtig 3SG lie:3SG:PRS in the basket but NEG properly 'It (a bottle) is (lit. 'is lying') in the basket but not properly' (Bochum Stimuli)

(35) a. Q: der Prospekt? the folder

b. C: Der liegt auch im Korb DEM lie:3SG:PRS also in:the basket

c. A: Aber der LIEGT nicht but DEM lie:3SG:PRS NEG

d. C: Im Zweifelsfall immer: IST im in:the case.of.doubt always be:3SG:PRS in:the Korb basket

e. A: Ich würd sagen, der LIEGT 1SG would:1SG:PRS say:INF DEM lie:3SG:PRS auch, obwohl er nicht LIEGT as.well although 3SG NEG lie:3SG:PRS Q: 'The folder?' - C: 'It is (lit. 'is lying') in the basket' - A: 'But it is not lying' — C: 'If in doubt: (it) IS in the basket' - A: 'I'd say, it is lying, although it is not lying'

Example (35) is the discussion of two speakers elicited with a folder in a basket, also in a diagonal configuration. In line (35b) and in the first clause in line (35e), the speakers use liegen, as is appropriate for the actual 
configuration of the folder being inside the container, but in line (35c) and the second clause in line (35e), the speaker considers the prototypical use of liegen, i.e., the configurations for which this positional would be appropriate outside a container, and therefore states that the folder does not lie.

The issue is further complicated by the fact that sein 'be' is also available as an underspecified locative verb in the case of containment (cf. [35d] above), and tends to be used for flexible containers like cloth bags. In a search of a subpart of the IDS corpus, no combination of liegen with a PP containing the nouns Tasche 'bag', Beutel 'cloth bag' or Sack 'sack' could be found. In our data, too, sein 'be' was preferred for configurations of this type.

\subsection{Hängen 'hang'}

In contrast to stehen 'stand', liegen 'lie' and also sitzen 'sit' (not considered here), the verb hängen 'hang' cannot be attributed to a typical posture of the human body, although it can be used with both animates and inanimates. The standard use of the verb hängen describes the relation of a Figure to its Ground that is only attached at one point - typically the highest part of the Figure - and lacks support from below. As a result, the configuration of the Figure is determined by gravity, i.e., normally from the point of attachment downwards (cf. Kaufmann 1995: 109). Animates, normally human beings, can for instance be said to 'hang' if they are "attached" to a cliff holding on to it with their hands without having support under their feet. Examples of inanimate Figures in our data comprise flexible entities such as ropes, pieces of cloth, or clothing (example (36)), and solid objects such as a picture on a wall (example (37)), or a stick in a tree being attached to a branch and dangling downwards (example (38)).

$\begin{array}{lll}\text { Die Wäsche hängt } & \text { an der Leine } \\ \text { the washing hang:3SG:PRS } & \text { on the line }\end{array}$

'The washing is hanging on the (washing) line'

(TRPS 37)

(37) Das Bild hängt im Keller

the picture hang:3SG:PRS in:the basement

'The picture is hanging in the basement'

(Gerling and Orthen 1979: 69)

Ein Stock hängt im Baum
a stick hang:3SG:PL in:the tree
'A stick is hanging in the tree'

(PSPV 55) 
The typical configuration for hängen also implies that the Figure dangles freely, as several speakers in our corpus stated who did not judge hängen to be appropriate for the position of a small earring in the shape of a ring.

(...) also wenn das jetz n Ohrring
well if DEM now a earring
wär der so baumelt,
be:3SG:SUBJUNCT REL thus dangle:3SG:PRS then
würd ich sagen hängt
AUX:1SG: SUBJUNCT 1SG say:INF hang:3SG:PRS
'(..) well, if it was an earring which kind of dangles, then I would
say "hang",

(TRPS 70)

However, hängen is not restricted to relations of attachment to a single point, nor to dangling objects but can be triggered by a configuration of lack of support from below only. Thus, as shown in (37), in Standard German hängen is the only proper positional for describing objects attached to walls (e.g., a telephone fixed to a wall, as in TRPS 25) unless the configuration is one of tight fit or adhesion, and even in those cases hängen can be found (cf. examples (64) to (67) in Section 3.8).

A less prototypical use of hängen is the one found in (40); the configuration is that of a ball which is stuck between two branches, one third of it being below its point of attachment. For this configuration, only 3 out of 8 speakers chose hängen, while others chose liegen 'lie' (see Section 3.3), stecken 'be in tight fit, be stuck' (see Section 3.6) or klemmen 'be stuck, be jammed' (see Section 3.7).

Der Ball hängt $\quad$ zwischen Ästen im
the ball hang:3SG:PRS between branches in:the tree
'The ball is hanging between branches in the tree'

(PSPV 43)

Marginally, the use of hängen is also possible in configurations where the Figure is oriented vertically with respect to a Ground below the Figure, as long as the Ground is not conceptualized as supporting the Figure from below. For instance, for a leaf "standing" erect on a branch (TRPS 41), hängen was accepted by all four consultants tested for this configuration. ${ }^{12}$

Gas-like Figures such as clouds or smoke, and, metaphorically, also smell can also be seen as lacking support from the Ground, and thus may trigger the use of hängen. A search of the IDS corpus also revealed a great many uses of this kind, where the characteristic common denominator seems to be a perceived "heaviness" of the cloud or gas-like Figure 
in question (e.g., a rain cloud, smog, a strong smell, or heavy smoke, the latter illustrated in [41]). This appears to confirm the observation that the meaning component of 'configuration being determined by gravity' is the most relevant for the use of hängen.

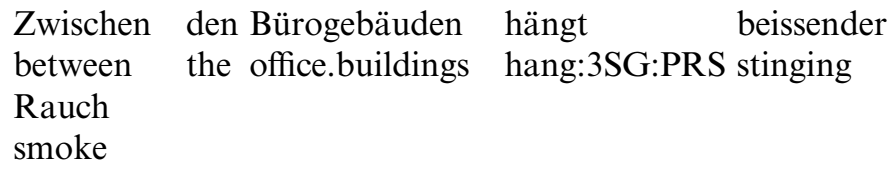

'In between the office buildings is (lit. 'is hanging') stinging smoke' (IDS E98/AUG.20825)

Clouds as Figures may also trigger the use of stehen 'stand' (since for celestial bodies this positional is conventionalized; see Note 10 in Section 3.2) or schweben 'be afloat' (see Section 3.10).

As already seen in the discussion of example (40), the use of hängen may overlap with that of other positionals such as klemmen or stecken. In these cases speakers choose to foreground the nature of the attachment of the Figure to the Ground. The pairs of responses in (42) and (43) were elicited with the same stimulus.
a. Die Wäscheklammer hängt am Saum the peg hang:3SG:PRS at:the hem
'The peg is hanging from the hem' (Bochum Stimuli)
b. Die Wäscheklammer klemmt the peg jam(ITR):3SG:PRS at the blouse 'The peg is stuck on the blouse' (Bochum Stimuli)
(43) a. Es hängt aus'm Regal
3SG hang:3SG:PRS out.of.the shelf
'It (a rope) is hanging from the shelf'
(Bochum Stimuli)
b. Es steckt unter den Büchern
3SG stick(ITR):3SG:PRS under the books
'It (a rope) is stuck under books'
(Bochum Stimuli)

In the noncanonical situation of a flexible object like a rope being horizontally positioned on branches in a tree (cf. PSPV 57) or leaves of a small palm tree (Bochum Stimuli), hängen may also be used and alternates with the positional liegen. The relation of Figure and Ground is noncanonical for the use of liegen as well, since even though the Figure is clearly horizontally oriented, it is only supported by the Ground at 
some points, while the portions of the Figure between these points lack support from below. In these cases, either the horizontal alignment may be foregrounded leading to the use of liegen, or the lack of support for most of the Figure may be emphasized by the choice of hängen, as is illustrated in (44) with two responses from the same speaker.

$$
\begin{array}{ll}
\text { a. Q: wo ist } & \text { das Seil? (..) } \\
\text { where be:3SG:PRS the rope } \\
\text { b. C: Liegt } & \text { in der Pflanze (..) } \\
\text { lie:3SG:PRS in the plant } \\
\text { hängt } & \text { in der Pflanze } \\
\text { hang:3SG:PRS in the plant }
\end{array}
$$

Q: 'Where is the rope?' - C: '(It) is lying in the plant ... hanging in the plant'

(Bochum Stimuli)

Since some speakers accept hängen even for nonflexible Figures such as small sticks positioned on the leaves of the same palm tree, the prototypical meaning component of 'lacking support from below' and not the more secondary component of 'dangling' seems to trigger the use of hängen.

\subsection{Lehnen 'lean'}

Similar to the verb hängen 'hang', lehnen 'lean' belongs to the group of positionals which entail contact between Figure and Ground. Unlike hängen, however, lehnen, at least with inanimates (since these are not able to support themselves in a skewed position with muscular force), is used for configurations where the Figure is in contact with two surfaces which are roughly orthogonal with respect to each other, e.g., a floor and a wall, as in (45), or a floor and a basket, as in (46). That is, this verb cannot be used where a Figure is in contact with a single surface only, even when it is supported in two different places. Thus the configuration of an opened umbrella touching the floor with its handle and with one of its spokes can only be described with the positionals stehen 'stand' or liegen 'lie'.

Furthermore, a Figure that can lehnen 'lean' has to be a solid rigid object, which can bear its own weight without being deformed. The verb therefore does not apply to flexible Figures such as ropes, pieces of cloth or items of clothing. The typical configurations - i.e., configurations for which all speakers agreed that lehnen was appropriate - involve rigid objects with a salient two-dimensional orientation. 
$\begin{array}{lll}\text { Die Leiter lehnt } & \text { an der Wand } \\ \text { the ladder lean:3SG:PRS at the wall }\end{array}$ 'The ladder is leaning on the wall' (TRPS 58)

(46) Der Stab lehnt an dem Korb the stick lean:3SG:PRS at the basket 'The stick is leaning on the basket' (PSPV 12)

Similarly, round objects, such as balls, cannot be conceptualized as being in a lehnen relationship to its Ground. For nonround objects such as cubes, lehnen can be used, since they can be tilted such that only the top and the bottom part of the object touch the respective Grounds.

Just like stehen 'stand', lehnen requires that the configuration be perceived as stable, and is therefore only marginally used or accepted for Figures inside a moveable container. For example, while all speakers agree on using lehnen for configurations such as a spoon leaning on a cup when the Figure is outside the container, for an object being inside a cup or a basket leaning on the rim, only one speaker agreed that lehnen could be used. In the following example, this use is immediately challenged by a second speaker.

D: Ich würd
1SG AUX:1SG:SUBJUNCT MOD.PTKL say:INF
"der (Löffel) lehnt
the spoon lean:3SG:PRS in the cup
A: man kann
one can:3SG:PRS NEG in something lean:INF
man kann
one can:3SG:PRS only at something lean:INF
D: 'I would possibly say "it (the spoon) is leaning in the cup".'
- A: 'One cannot lean IN something, one can only lean ON
something'
(Bochum Stimuli)

The other speakers described similar configurations with the verbs stecken or stehen in case of a narrow container such as a cup or a bowl (see (26) and Section 3.6), with liegen for a container with a wider opening, e.g., a basket (see Section 3.3), with stehen if the Figure was very clearly in an upright position (see Section 3.2), and otherwise with sein 'be'. The findings in our elicitation sessions were confirmed by means of the IDS corpus, where a search for lehnt + in did not return any example with a container as the Ground and the Figure perceived as 'leaning' inside this container. 
Overlaps between stehen and lehnen can also be found for Figures which are not in a container, such as a broom or a ladder leaning on a wall, irrespective of whether they have a base or not. The angle between Figure and supporting Ground seems to be the essential feature. If the angle is rather small and the Figure is seen as being more or less upright, for some speakers stehen is preferred over lehnen, even if the Figure is supported from the side as well as from below. (Both liegen and lehnen may be used if the longest axis of the Figure in question has a horizontal extension and its shorter axis is supported from the side, e.g., in the case of a hammer leaning against a box). In the cases of possible overlap stehen and lehnen may also occur together in secondary predicate constructions. In these cases stehen is the main predicate while the past participle of lehnen or its particle verb derivation anlehnen 'lean against' is the secondary predicate of the construction, as is illustrated in (48).

Der (Teller) steht
the plate stand:3SG:PRS at:the printer
angelehnt
lean:PTCP.PERF
'The plate is (lit. 'stands') leaned against the printer'
(Bochum Stimuli)

\subsection{Stecken 'be in tight fit, be stuck, stick(ITR)'13}

Unlike the other positional verbs discussed so far, stecken cannot be defined in terms of support, but rather in terms of a specific containment relation between Figure and Ground: the Figure and the Ground are in a relation of tight fit (as also indicated in the dictionary definition of 'fitting, be fastened' in the DUDEN). Typical examples of a stecken configuration are that of a cork in a bottle, a foot in a shoe (see (57) below), a plug in a socket, a CD in its cover, a key in a keyhole, a candle in a candle stand (see (49)), and a stick which is partially embedded in the ground and therefore stays upright. Thus, all 8 speakers used stecken to describe the stimulus in PSPV 20; an example is (50).

\begin{tabular}{|c|c|c|}
\hline (49) & $\begin{array}{llll}\text { Die } & \text { Kerze } & \text { steckt } & \text { im } \\
\text { the } & \text { candle } & \text { stick(ITR):3SG:PRS } & \text { in:the }\end{array}$ & $\begin{array}{l}\text { Kerzenständer } \\
\text { candlestick }\end{array}$ \\
\hline & $\begin{array}{l}\text { 'The candle "is stuck" in the candlestick' } \\
\text { (Bochum Stimuli) }\end{array}$ & \\
\hline (50) & $\begin{array}{llll}\text { Der } & \text { Stock } & \text { steckt } & \text { im } \\
\text { the } & \text { stick } & \text { stick(ITR):3SG:PRS } & \text { in:the }\end{array}$ & $\begin{array}{l}\text { Boden } \\
\text { ground }\end{array}$ \\
\hline
\end{tabular}


As these examples show, the orientation of the Figure is irrelevant, and the containment may be partial or complete. Our findings therefore contradict Coseriu (1968: 9), who assigns the semantic feature of 'invisible position' to stecken (an analysis which is also taken over by Kotschi [1974: 138-148] and Gerling and Orthen [1979: 68f.]). That the relation of tight fit is seen as a criterion for the use of stecken also becomes apparent from the following statement of a speaker, who was justifying her choice of stecken to describe a CD in its cover.

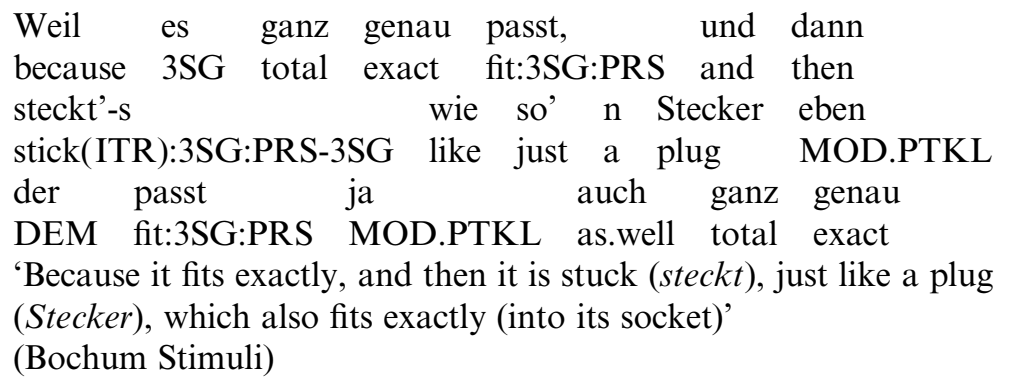

However, stecken is not restricted to relations of "exact" fit (as claimed by the speaker in (51)). Rather, this verb displays an interesting prototype effect in that speakers disagree in how far to extend the use of stecken to relations of rather loose fit. For example, while stecken is accepted by all speakers in descriptions of small objects in a pocket, it is used or accepted by fewer speakers to describe objects in a larger flexible bag, especially if the object or objects do not fill the bag more or less completely. The other speakers only accept the general locative verb sein (see Section 4.3). A search of the IDS Corpus for stecken with the Ground nominals Tasche 'bag, pocket' and Sack 'Sack' returned few examples, and these all described configurations of tight fit.

Similarly, multiple extended objects in a rigid container which is open at the top are more readily described as in a stecken relation than a single object of the same type in the same container, since the multiple objects are more tightly packaged, as it were (although still not fitting "exactly"). For example, multiple toothbrushes in a glass can be described as in (52) and the configuration in PSPV 60 (four bottles in a basket), can be described as in (53).

(52) Deine Zahnbürsten stecken
POSS:2SG toothbrushes stick(ITR):3PL:PRS in:the
Zahnputzbecher
toothbrush.glass
'Your toothbrushes "are stuck" in the toothbrush glass'
(Bochum Stimuli)




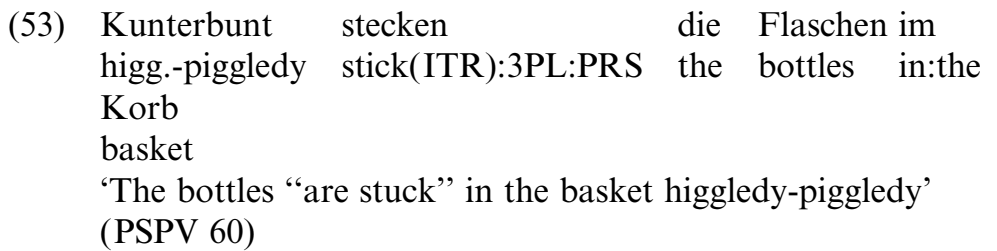

In contrast, no speaker used stecken to describe any of the PSPV stimuli depicting a single bottle in a basket (PSPV 22, 62, and 67). Depending on the actual configuration, stehen 'stand', liegen 'lie' or sein 'be' are preferred in this case. Similarly, speakers disagreed on the appropriate description of a single toothbrush, pen or a spoon placed upright in a cup, mug or small bowl (which was otherwise empty). For these configurations, elicited with real objects, 6 out of 14 speakers used or accepted stecken, although two later corrected their own spontaneous use of stecken (see example (78)). The others again preferred stehen 'stand' (see example (26)), sein 'be', or (marginally) lehnen 'lean' (see example (47)).

Another interesting observation about stecken is that it displays FigureGround reversal of the type described by Kita (to appear) for the Japanese verb sasuru 'be in piercing relation': both the contained and the containing entity can be construed as the Figure. Examples (49) to (53) above and (56b) below illustrate the first possibility; the second possibility is illustrated in (54) to (56a).

Der Ring steckt

am Finger

the ring stick(ITR):3SG:PRS at:the finger

'the ring "is stuck" on the finger'

(TRPS 10)

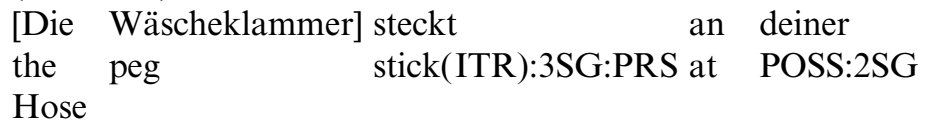

trousers

'(the peg) 'is stuck" on your trousers' (the relevant part of the trousers is contained between the two ends of the peg)

(Bochum Stimuli)

(56) a. [Der Apfel] steckt auf diesem spitzen the apple stick(ITR):3SG:PRS on DEM pointed Dingens

thing

'(the apple) "is stuck" on that pointed/sharp thing'

(TRPS 70) 
the Figure itself which is fastened on a Ground by means of two of its parts which exert pressure on (a part of) the Ground (note that the noun (Wäsche-) Klammer is a cognate of klemmen).

(58) Ein Ball klemmt zwischen zwei Ästen a ball jam(ITR):3SG:PRS between two branches 'A ball is stuck between two branches' (PSPV 44)

(59) Die Wäscheklammer klemmt an der Bluse the peg jam(ITR):3SG:PRS at the blouse "The peg "is stuck" on the blouse' (Bochum Stimuli)

In descriptions of the stimuli used in elicitation for this study, klemmen is very marginal. Examples (58) and (59) are the only spontaneous uses as a simple positional in the BLC in our data (the verb was accepted by other speakers for the same stimuli, though). Moreover, Klemmen and particle verbs based on klemmen were used in the result construction and as a secondary predicate in the BLC with another positional as the main predicate, as in (60) - a response to the same stimulus as in (58) - and in (61).

$\begin{array}{llllll}\text { (60) Ein Fußball hängt } & \text { in eim } & \text { Baum } & \text { zwischen } \\ \text { a football hang:3SG:PRS in a } & \text { tree } & \text { between } \\ \text { zwei } & \text { Ästen } & \text { eingeklemmt } & & & \\ \text { two branches jam:PTCP.PERF } & & \end{array}$

'A football is hanging in a tree, jammed between two branches' (PSPV 44)

(61) Es steckt im Drucker //

3SG stick(ITR):3SG:PRS in:the printer

fest-geklemmt

tight-jam:PTCP.PERF

'It (a rope) is stuck in the printer, jammed'

(Bochum Stimuli)

Two factors seem to be responsible for the marginality of klemmen. The first is its semantic overlap, already illustrated in (60) and (61), with both stecken 'be stuck' (which shares with klemmen the component of 'tight fit') and with hängen 'hang' (which shares with klemmen the component of 'attachment without support from below'). Thus, for the configurations described in (58) and (59), these two verbs were the more frequent alternatives.

The second factor seems to lie in a conventionalized use of klemmen without a Ground expression, to express an undesired state of affairs 
where parts of an object which are normally movable are jammed, e.g., in die Schublade klemmt 'the drawer jams' or die Maschine klemmt '(a part of ) the machine jams'. This reading of klemmen was in fact given by one speaker as the reason for not accepting klemmen even for the configurations in (58) and (59).

\subsection{Kleben 'stick by means of glue', haften 'adhere'}

Our data confirm dictionary definitions according to which the verb kleben implies a configuration of contact between Figure and Ground caused by a sticky substance such as glue, like that of a stamp on a letter or adhesive tape on a leg; the latter illustrated in (62) (see also Kaufmann 1995: 118). This verb will be glossed as 'stick (glue)' to distinguish it from stecken 'stick(ITR)'.

Das Pflaster klebt
the adhesive.tape
kurz über dem Knöchel
just above the ankle
'The adhesive tape sticks on the shin just above the ankle'
(TRPS 35)

More precisely, though, the Figure itself could be a sticky substance, as with chewing gum being stuck at the bottomside of a table (TRPS 53) or jam on a knife, where most of the speakers in our data used kleben, as in (63).

$\begin{array}{lll}\text { Die Marmelade klebt } & \text { am } & \text { Messer } \\ \text { the jam stick(glue):3SG:PRS } & \text { at:the } & \text { knife } \\ \text { 'The jam sticks on the knife' } & & \end{array}$

(TRPS 12)

Some speakers in our data extend the use of kleben to configurations of adhesion even where no sticky substance is involved. For example, for the picture in PSPV 68, showing a piece of cloth fixed to the side of a tree stump, 3 out of 8 speakers used or accepted kleben; the others used hängen 'hang' (downplaying the component of adhesion of the whole piece of cloth), haften 'adhere' or haken 'get caught'. ${ }^{15}$ Two of the eight speakers, however, explicitly rejected kleben because it was not apparent that a sticky substance was responsible for attaching the Figure to its Ground.

Another case where speakers only accepted kleben with hesitations or not at all is that of a magnet stuck e.g., on a wall or a fridge. Here, of 
course, magnetism and not a sticky substance is responsible for the maintenance of the configuration. The parenthesis $n$ Magnet klebt natürlich auch, in the folk definition of the speaker in (64), shows a certain insecurity about his own definition of kleben in that, although he recognizes the semantic component of "stickiness" (hence Klebstoff 'glue'), he allows for the possibility of applying this positional to a magnet on an iron wall.

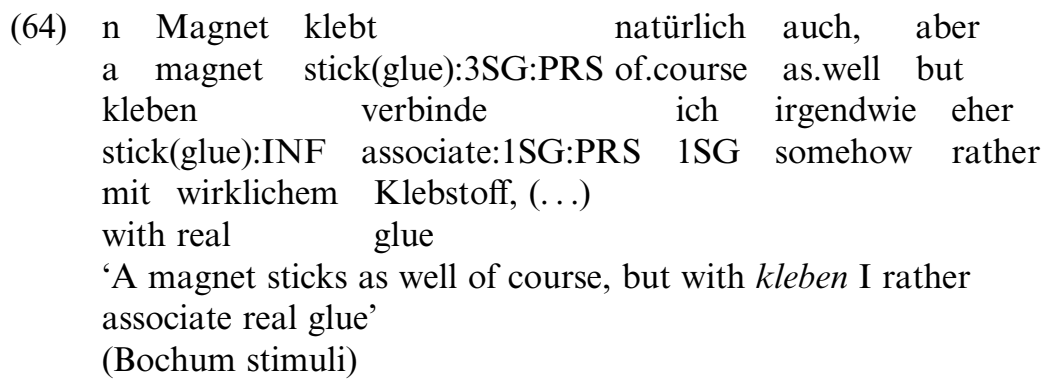

In descriptions of the same configuration, other speakers reject kleben and use hängen 'hang' (see Section 3.4) or haften 'adhere' instead:
(65) Die Magnete hängen an $\operatorname{der}(\ldots)$ Kühlschranktür the magnets hang:3PL:PRS at the door.of.fridge 'The magnets hang at the (...) door of the fridge'
(Bochum Stimuli)
(66) Der Magnet haftet an der Wand the magnet adhere:3SG:PRS at the wall
'The magnet is attached to the wall'
(Bochum Stimuli)

According to dictionary entries for haften, this verb is a positional that can be interchanged with kleben in case of describing configurations brought about by "stickiness". Thus, the example sentence for haften in the Wahrig dictionary (Das Pflaster haftet gut 'The plaster adheres well') corresponds to the stimulus in TRPS 35 for which all of the speakers in our sample used kleben, as in (62) above. Similarly, the speaker in (67) uses haften and accepts kleben for the "cloth on a tree stump" configuration in PSPV 68.

(67) Q: Klebt? stick(glue):3SG:PRS
A: Sieht
so aus zum Beispiel ja look:3SG:PRS like PTKL for example yes
Q: Und befestigt? and fix:PTCP.PERF 
$\begin{array}{llllll}\text { A: } & \text { Nee der } & \text { scheint } & \text { da } & \text { aus eigenen } \\ \text { no DEM } & \text { seem:3SG:PRS } & \text { there } & \text { out.of } & \text { own } \\ \text { Stücken } & \text { zu } & \text { haften } & & & \\ \text { power } \quad \text { INF } & \text { adhere:INF } & & & \end{array}$

Q: 'Sticks?' - A: 'It looks like it, for example, yes' — Q: 'What about "is fixed"'? - A: 'No, it seems to adhere out of its own power'

(PSPV 67)

However, the fact that haften is more readily accepted for magnets - a search of a subpart of the IDS corpus returned no uses of kleben with a magnet as a Figure, but seven uses of haften - suggests that it only entails adhesion as such, not adhesion brought about by a sticky substance, and is thus semantically somewhat less specific than kleben. Despite this fact, haften is marginal in our data outside the examples just mentioned; our own impression is that it is more or less restricted to written German.

\subsection{Schwimmen 'be afloat in liquid'}

The verb schwimmen 'be afloat in liquid' in German has two readings. As a motion verb it can be used in constructions with path expressions just like its English translation equivalent and cognate, swim. The second reading is that of a stative locative verb (cf. also Kaufmann 1995: 99f.). In Wahrig's dictionary it is glossed as 'be carried (i.e., afloat) in a liquid, not sink'. Our data also clearly show that schwimmen does not entail translational motion, but only entails that a Figure is afloat on or in the liquid, i.e., supported by the liquid. It is regularly employed with inanimate, nonmoving Figures, and the orientation or shape of the Figure are irrelevant.

Schwimmen is not applicable if the Figure is immersed in liquid, but touches the Ground rather than being afloat. In this case the positional appropriate for the orientation of the Figure - usually liegen - is used. For example, the following brief exchange was elicited by a small object (a tube of cream) which slowly sank to the bottom of a washing bowl filled with water.

(68) A: Die schwimmt (..) die schwamm in der DEM swim:3SG:PRS DEM swim:3SG:PST in the Schüssel bowl

Q: Und jetzt? and now 
B: Liegt sie am Grund der Schüssel lie:3SG:PRS 3SG at:the bottom of:the bowl

A: 'It swims ... it swam in the bowl' — Q: 'And now?' - B: 'It is lying on the bottom of the bowl' (Bochum Stimuli)

If the Figure is motionless right on the surface of the water (as in the case of a cork or a boat), liegen may also be used as an alternative to schwimmen.

\subsection{Schweben 'be afloat'}

The verb schweben 'be afloat' may take part in constructions with path expressions, but, like schwimmen, it is not only a motion verb but is found in the BLC as well, with a stative reading. Like schwimmen, it is explicitly classified as a stative locative verb by Kaufmann (1995: 120). Dictionary definitions tend to classify schweben as a motion verb meaning 'hover along slowly', etymologically originating in 'moving to and fro' (Wahrig), but usually also include examples with stative readings of the verb. In our data, schweben is used for expressing Figure-Ground relations of objects such as clouds, where the Figure is not being supported or attached to its Ground, although, as is illustrated in (69), some speakers reject it as being poetic language:

(69) a. Die Wolke schwebt über dem Berg the cloud float(ITR):3SG:PRS above the mountain 'The cloud is (lit. 'is afloat') above the mountain' (TRPS 36)

b. A: Die Wolke steht am Himmel (...) the cloud stand:3SG:PRS at:the sky

Q: Schwebt? float(ITR):3SG:PRS

A: Nee würd ich nie sagen! no AUX:1SG:SUBJUNCT 1SG never say:INF $\mathrm{Da}$ is ja höchstens, then be:3SG:PRS MOD.PTKL only ich bin doch kein Dichter! 1SG be:1SG:PRS MOD.PTKL NEG poet

A: 'The cloud is (lit. 'is standing') in the sky' — Q: 'Is afloat?' — A: 'No, I would never say so! That is only, well, I am not a poet, you know!'

(TRPS 36) 
Contrary to what is stated by Kaufmann (1995: 99), the use of schweben is not restricted to a gas-like medium. Rather, expressions with schweben may describe Figures lacking support by a solid Ground, which typically means that they are floating in the air, but could also mean that they are afloat in water, as in (70), or that they are lacking any support at all, e.g., in case of astronauts in the gravity free surrounding of outer space in (71).

(70) Die schwebt irgendwie

DEM float(ITR):3SG:PRS somehow

'it is afloat somehow' (tube afloat in water)

(Bochum Stimuli)

(71) Die Astronauten schweben über der Luke

the astronauts float(ITR):3PL:PRS above the door

des Raumschiffs

of.the space.shuttle

'The astronauts are (lit. 'are afloat') over the door of the space shuttle'

For Figures being afloat in a liquid, the more specific verb schwimmen 'be afloat in liquid' (see Section 3.9) overlaps in usage with the less specific verb schweben. In case of gas-like Figures, schweben is replaced by hängen if the gas-like Figure is conceptualized as heavy and subject to gravity (see Section 3.4 for discussion and examples).

\section{Conditions of use of the general locative verb sein 'be'}

As already indicated in Section 1, German has a semantically general locative/copular verb sein 'be', in addition to the more specific positional verbs discussed in Section 3. This also has a variant which mainly occurs in the written register and was only occasionally found in our data, sich befinden 'be located' (lit. 'be found'). From a structuralist semantic approach, represented e.g., by Kotschi (1974: 146-148) and Gerling and Orthen (1979: 53), sein 'be' can be regarded as an archisememe which is semantically underspecified except for the semantic feature "static location", and therefore can be substituted for any of the positional verbs. This analysis can be confirmed in elicitation: speakers readily accept the verb sein in the BLC in virtually all contexts. In actual usage, however, the semantically specific positional verbs are strongly preferred (at least in the variety of German examined here). For example, in only 25 of 544 spontaneous first responses elicited with the PSPV Stimuli, sein or sich 
befinden were employed. Admittedly, these Stimuli depict rather marked configurations, which are more likely to trigger the use of a specific positional, and the proportion of sein responses is somewhat higher for the TRPS Stimuli, depicting mostly unmarked configurations.

There are, however, several contexts where the use of the underspecified verbs appears to be more felicitous, or is even required. These contexts can be divided into three main types: First, the position of the Figure in question may not be known - e.g., in a 'where' question, or if the Figure is invisible. Second, the Figure may be of a type (e.g., a mass) that does not allow for the specification of a position, and hence for the use of a positional verb. Third, and most interesting in the context of this study, there may be no positional that is appropriate to describe a certain configuration, either because the configuration does not have the stereotypical features corresponding to any positional, or because multiple Figures have different positions, i.e., cannot be described by any single verb. These possibilities will be discussed in turn.

\subsection{Unknown configuration}

Since German positional verbs classify referents according to their actual configuration, not according to the canonical configuration that the class of referents normally occur in, it is predicted that the semantically underspecified general locative/copular verb sein 'be' should be preferred when the position of the Figure is not known, as for example in 'where' questions, in negative presentational (see Section 2.2) or locative statements, or when the Figure is located in a closed container or otherwise invisible. This is not a strict requirement, however, since many types of Figures have a stereotypical orientation, that is, their configuration can be predicted even in the absence of direct evidence, and in this case the appropriate positional may be used. Note that this does not, strictly speaking, amount to a "presuppositional" use of the positional (as defined by Ameka and Levinson, this issue), since the positional is not automatically associated with a canonical configuration, but is only used if the actual configuration of the referent can be predicted. The following dialogue can serve to illustrate this point. It was uttered during an elicitation session, but can be regarded as more or less natural speech because the Figure, a newly acquired printer, was of real interest to the participants in the dialogue.

(72) a. S: Und der neue Farbdrucker? 
b. M: Der ist noch in der Kömme,

DEM be:3SG:PRS still in the box weiß ich nicht, wo ist know:1SG:PRS 1SG NEG where be:3SG:PRS der?

DEM

c. S: Nee, der ist schon

no DEM AUX:3SG:PRS already

ausgepackt $[\ldots]$ ist schon unpack:PTCP.PERF AUX:3SG:PRS already installiert install:PTCP.PERF

d. M: Ist schon installiert, AUX:3SG:PRS already install:PTCP.PERF ja wo steht der denn? MOD.PTKL where stand:3SG:PRS DEM then

e. S: Nebenan next.door

S: 'And (where is) the new color printer?' - M: 'It is still in the box, I don't know, where is it?' - S: 'No, it is already unpacked [...] it is already installed.' - M: '(It) is already installed, well where is it (lit. 'standing') then?' - S: 'Next door'

(Bochum Stimuli)

This dialogue contains two "where" questions by the same speaker inquiring about the same object, a printer. The first time (72b) the speaker assumes that the printer is in a closed container (a box), in an unknown orientation. Correspondingly, the verb used here is the general locative verb (just as in his own response, in the same line, to the 'where' question posed by the investigator). At the time that the speaker asks his question again $(72 \mathrm{~d})$, he has reason to assume that the printer is in its canonical orientation, that is, placed on its inherent base, since he has been told that it is already unpacked and installed. This time, he uses the positional appropriate for Figures with an inherent base, stehen 'stand'. Another example of the latter type is (21), where stehen is also used for an object - a video recorder - in a closed cupboard, because it can be expected to be in its canonical position.

Questions about, and descriptions of the location of an object with an unknown configuration, and negative existential or locative statements, are difficult to elicit. In order to present a comprehensive account of the factors influencing the choice of the underspecified verb vs. the specific 
positionals, it would therefore be necessary to work with a large corpus of natural speech which is centered around locative descriptions. Such a study is beyond the scope of the present paper. In our elicited materials, there is, however, good evidence that the location of Figures in a closed container is more often described with sein (just as in [72b]) than with a positional verb. We also have anecdotal evidence that in "where" questions and negative existential or locative statements, the underspecified locative verb tends to be used. As shown in (72), (21) and also (11), this is no hard and fast restriction; if the configuration is stereotypical, a positional is still appropriate.

\subsection{Nonpositionable Figures}

Even if a Figure and its configuration are visible, the verb sein 'be' is the only possibility for locating "figures" that have no clear gestalt-like shape, e.g., liquids, or which are nondetachable parts of the Ground, e.g., handles. The latter category also includes negative Figures like holes. Thus, in (73) to (75), sein cannot be replaced with any of the positional verbs.

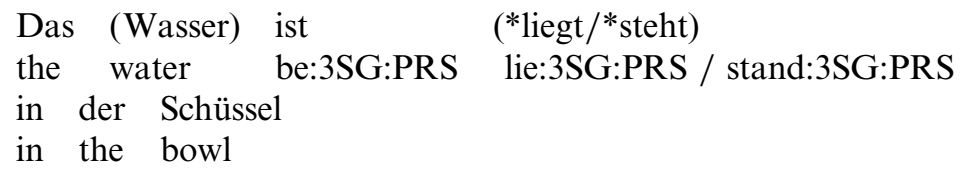

'The water is in the bowl'

(Bochum Stimuli)

(74) Der Griff ist (*steckt/*hängt) an

the handle be:3SG:PRS lie:3SG:PRS / hang:3SG:PRS at

der offenen Tür

the open door

'The handle is on the open door'

(TRPS 61)

(75) Der Sprung ist (*liegt/*steckt)

the crack be:3SG:PRS lie:3SG:PRS / stick(ITR):3SG:PRS

in der Tasse

in the cup

'The crack is in the cup'

(TRPS 26)

The verb stehen is acceptable with liquids in combination with a directional phrase or a measure phrase, as in (76). These expressions, however, 
are not felicitous as answers to a 'where' question and hence do not fall under the BLC.

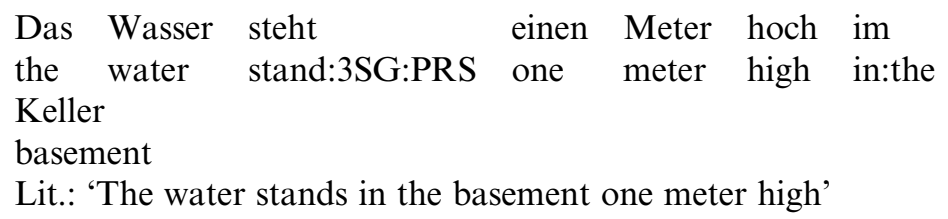

Similarly, as one anonymous reviewer has pointed out, liegen 'lie' does occur in collocation with 'water'. However, as a search of the IDS corpus confirmed, this use is restricted to large expanses of water such as lakes, or the ground water, and is usually followed by an adverb such as 'calmly', not by a locative phrase. If found with a locative adverbial, this use of liegen comes very close to the use of liegen with named locations (e.g., Köln liegt am Rhein 'Cologne is located on the Rhine'). Both an adverb and a locative adverbial are combined in (77).

(77) Das Wasser liegt
the water lie:3SG:PRS $\begin{aligned} & \text { inmitten von } \begin{array}{l}\text { Bäumen } \\ \text { amidst of trees }\end{array} \\ & \text { da }\end{aligned}$ calmly
there
Lit.: 'The water lies calmly amidst trees'

Masses like butter and granular substances like sand or sugar constitute borderline cases. For substances of this type, liegen 'lie' is appropriate when they are supported by a surface, just as for any object lacking a base, including multiple small near-symmetrical objects like beans (see example (33) in Section 3.3). However, when they are in a container, only sein can be used for all of these Figures.

\subsection{Inapplicability of positionals}

If, in the case of a "good", moveable, visible Figure, sein 'be' rather than one of the positional verbs is used, this is always because none of the positionals applies to the configuration in question. These "difficult" configurations fall into two main types: containment, and multiple Figures assuming different orientations.

It has been pointed out in various places in this paper that the choice of positional verbs is reduced for containers as Grounds. If the container is rigid (e.g., a basket) and the Figure is more or less completely contained 
in it, liegen 'lie' can often be used as the residual positional verb (see Section 3.3), although sein is also frequent, and indeed tends to be used if the containment is not complete. The residual character of sein is illustrated in (78), the responses from a single speaker to a configuration of a spoon protruding from a bowl of roughly equal dimensions. The speaker here first considers three positionals as potential candidates, but then decides on sein as a last resort since none of the other verbs are judged appropriate: the configuration does not have any of the components of tight fit (required for stecken), presence of a base or of clearly vertical extension (required for stehen) or horizontal extension or complete containment (required for liegen).
a. Der Löffel steckt
in der Schale
the spoon stick(ITR):3SG:PRS in the bowl
b. Steht in der Schale stand:3SG:PRS in the bowl
c. Liegt in der Schale lie:3SG:PRS in the bowl
d. Liegt? (...) Steckt? (...) ich weiß lie:3SG:PRS stick(ITR):3SG:PRS 1SG know:1SG:PRS aber wirklich nicht. Steckt? (...) but really NEG stick(ITR):3SG:PRS
e. (...) Der Löffel IST in der Schale the spoon be:3SG:PRS in the bowl "The spoon "is stuck" in the bowl. Is standing in the bowl. Is lying in the bowl. Lies? Is stuck? I really don't know. Is stuck? The spoon IS in the bowl' (Bochum Stimuli)

While for objects in rigid containers specific positional verbs may be used under certain conditions, this is not possible for flexible containers like paper or cotton bags (see also the comments in Section 3.3). Some speakers accepted stecken 'be in tight fit, be stuck' if the Figure filled the bag more or less completely (see Section 3.6), but most speakers only produced and accepted sein 'be' in this case.

Responses to stimuli with multiple Figures in different configurations also show that sein 'be' is used as the last resort. For example, for Stimulus 46 in the PSPV stimuli, depicting several bottles on a table, some upright, some on their sides, 5 out of 8 speakers used sein 'be' (or its variant sich befinden) in one of their spontaneous responses; however, all but two of these speakers in addition also specified the respective positions of the bottles in separate clauses, as in (79). 
(79) Die Flaschen (...) sind auf dem Tisch, teilweise the bottles be:3PL:PRS on the table partly liegen sie teilweise stehen sie auf dem lie:3PL:PRS 3PL partly stand:3PL:PRS 3PL on the Tisch table

'The bottles are on the table, partly they are lying, partly they are standing on the table' (PSPV 46)

\section{Summary}

The discussion of the use of German positional verbs in the Basic Locative Construction (BLC) has shown that colloquial Standard German should be regarded as a positional language (or multiverb language) in the typology proposed by Ameka and Levinson (this issue). It has a set of around ten positional verbs that are regularly used to describe the configuration of moveable inanimate objects. As shown in Section 3.1, a considerable number of additional positional and locative verbs exist which are restricted to animate Figures, or have additional semantic features such as permanence of location, rather than encoding the locative relation as such. All of these stative locative verbs have a common formal property in that they more or less obligatorily take a prepositional phrase representing a location (see Section 2.1). The subset of verbs discussed here, however, could only be delimited from other stative locative verbs by semantic criteria.

As predicted for a positional language, the use of positionals in German always depends on the actual configuration of the entities involved. If the configuration cannot be seen or at least be predicted, a default verb, the unspecified locative/copular verb sein 'be', is used. On the other hand, on a scale based on the size of the positional verb class, German occupies a position at the lower end of the range of positional/multiverb languages. It is perhaps for this reason that German also shows a trait predicted for postural verb languages: positionals can be omitted, in which case only the prepositional phrase is used in an answer to a 'where' question, and one of a relatively large set of spatial prepositions conveys sufficient information about the configuration (see Section 2.1).

The flow chart in Figure 1 summarizes the factors influencing the choice of a positional verb in German, which were discussed in Sections 3 and 4. The general locative/copular verb sein 'be' (Section 4) functions as a residual positional verb, in that it is used if none of the more specific 


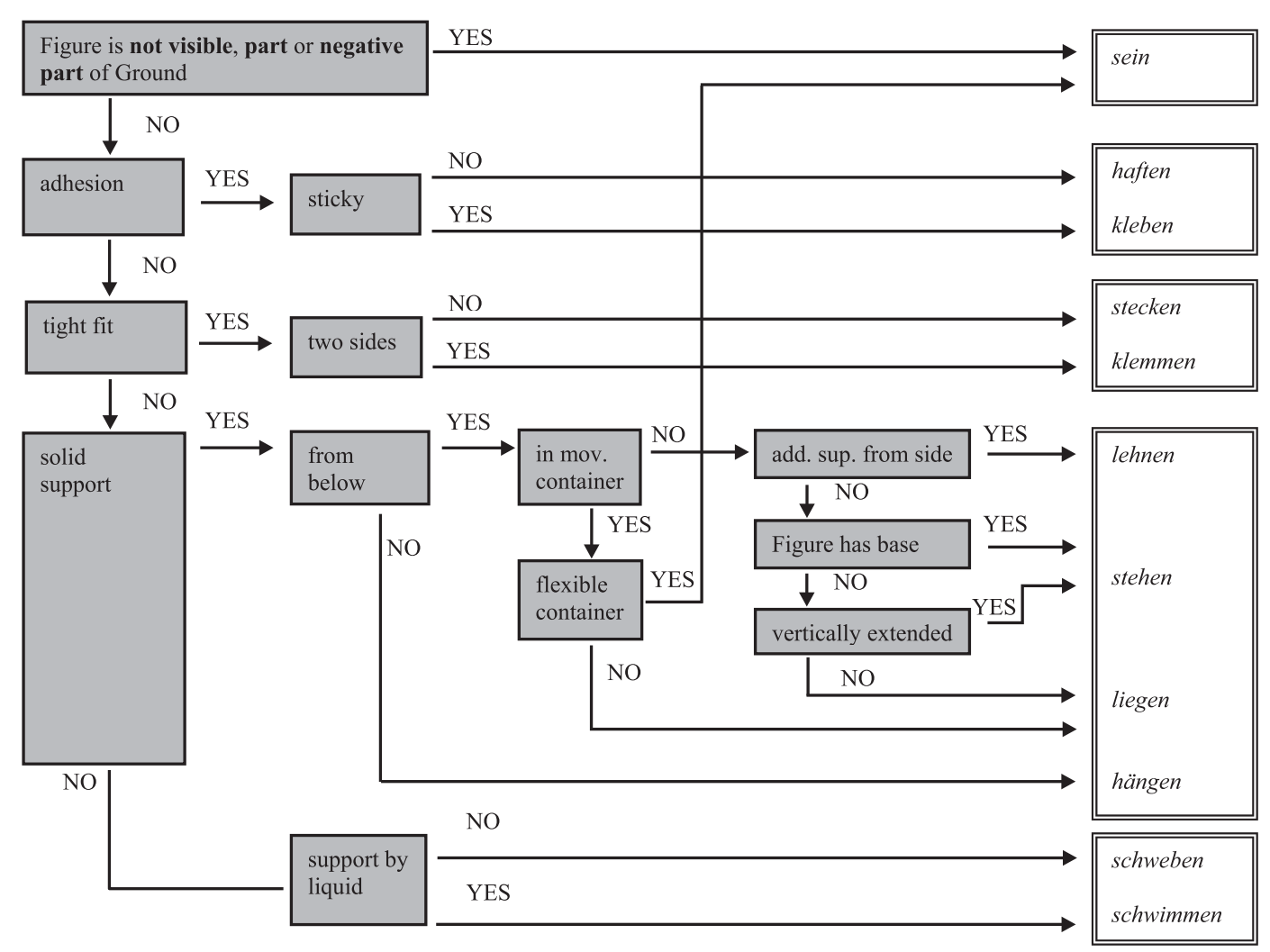

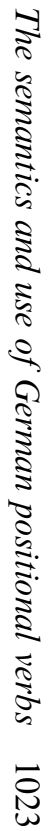

Figure 1. Factors influencing the choice of German positional vers 
verbs is completely appropriate for the description of a specific configuration (e.g., when multiple Figures have different configurations, or the Figure is in a nonprototypical position), and also if the actual configuration is not known and cannot be predicted. Sein 'be' (or its more literary counterpart, sich befinden 'be located') is also generally used for nonpositionable Figures, including masses, parts and negative parts.

The semantically specific positional verbs can be subdivided into subgroups according to the type of configuration or contact. Two verbs are restricted to "floating" Figures, i.e., configurations where the Figure is not supported by or contained in a solid entity of any sort. Of these, schwimmen 'be afloat in liquid' (Section 3.9) has an additional component of 'liquid medium', whereas schweben 'be afloat' (Section 3.10) is neutral in this respect. Both of these verbs have motion readings as well, but do not have transitive counterparts with the meaning 'place into Ving position', while for all remaining verbs, such counterparts exist.

Two further verbs are used to describe configurations of adhesion; the verb kleben, which requires adhesion by means of a sticky substance such as glue (or inherent stickiness of the Figure), is more frequent than the semantically more general but less colloquial haften 'adhere' (Section 3.8).

Two verbs are restricted to configurations of tight fit; these are stecken 'be in tight fit, be stuck' (Section 3.6) and klemmen 'be stuck, be jammed' (Section 3.7), which requires tight fit from two sides and can usually be replaced by stecken. These two verbs allow for an alternation in argument structure in that both Figure and Ground can be represented by the subject and the noun of the locative phrase, respectively.

Configurations of containment that are not characterized by tight fit are either described with the nonspecific locative verb sein 'be' - which is the only option if the container is itself flexible - or with liegen 'lie', which in this respect has some properties of a residual verb. As reflected in the title of this paper, the prototypical use of liegen is for Figures which do not have a salient vertical extension or a base, but this verb can be generalized to all Figures in a (rigid) container, at least if this is a container such as a basket or a box (see Section 3.3) which is not associated with a canonical position of the Figure. Presumably, in this case, liegen is chosen over lehnen 'lean' or stehen 'stand' because the configuration is not perceived as stable enough to warrant the use of one of the latter verbs.

The four remaining positional verbs share the component of 'support'; three of them require support from below, while hängen 'hang' (Section 3.4) is the appropriate verb for any kind of support that is not from below. The verb lehnen 'lean' (Section 3.5) entails that a solid Figure is supported both from below and from the side (i.e., from a surface orthogonal to the horizontal surface). The verbs stehen 'stand' (Section 3.2) and 
liegen 'lie' (Section 3.3), finally, are in direct opposition: both require support from below only, and differ in that stehen applies to Figures which either have an inherent base or are vertically extended, and liegen applies to all other Figures, e.g., Figures which are horizontally extended or symmetrical. The use of the verb sitzen 'sit' with inanimate Figures is restricted to a few idiomatic expressions in German and was not considered here.

Apart from stehen 'stand' und liegen 'lie', none of the positionals semantically encodes information about the shape of the Figure, and there are no positionals distinguishing between single Figures and aggregates. Apart from the general distinction between 'support by solid Ground' (most positionals), 'support by liquid' (schwimmen 'be afloat in liquid') and 'lack of perceived support' (schweben 'be afloat'), German positionals do not encode information about the nature of the Ground either - for example, German does not have a specific verb for a fire as the Ground. Thus, as a generalization, German positionals only distinguish between different types of contact and support.

Finally, we will consider the use of the positionals and of the locative/ copular verb sein 'be' in relation to the BLC hierarchy proposed by David Wilkins, as summarized in the introduction to this issue. As is predicted by the hierarchy, in German, moveable objects (position VI in the hierarchy) allow for the BLC and for a choice of locative verbs which is only restricted by the actual configuration of the Figure. In some points, however, the German data reported here contradict the hierarchy. Thus, the BLC is also used for Figures which are moveable in principle, but attached firmly to the Ground, or in a piercing configuration, although these are judged to occupy the highest positions (I and II) on the hierarchy and therefore should be least likely to allow for the BLC. In German, special positionals occurring in the BLC, such as kleben 'stick by means of glue' and stecken 'be stuck, be in tight fit' are used for these configurations. For most types of clothing and adornment (position V), likewise, the BLC with a positional verb such as stecken 'be stuck, be in tight fit' or hängen 'hang' can be used. For part/whole configurations (where the part is not detachable) and negative spaces, the BLC is also used. However, the only locative verb that can be used in these cases is the semantically general locative/copular verb sein 'be' (recall that in Section 1 we have argued that there is no evidence for considering expressions involving this verb as instances of a different construction from expressions involving a positional or other locative verb, since the criterion that the Ground PP is obligatory is met by all these verbs). The only configuration considered in the BLC hierarchy which, in German, does not allow for the use of a BLC at all is the configuration of encirclement. As pointed 
out in Section 2.4, a configuration of this type can only be described by means of the result construction, which, as shown by the responses to our stimuli, is also an alternative for most other configurations, but is used much less frequently than the BLC.

Received 8 June 2005

Revised version received

22 January 2007

\author{
University of Cologne \\ University of Manchester
}

\section{Notes}

1. We would like to thank all students, friends, and family members who agreed to respond (or were coerced into responding) to the various stimuli used in collecting the data for this paper. For comments on a previous draft of this paper, we are grateful to Felix Ameka, James Essegbey, Birgit Hellwig, and an anonymous reviewer. Correspondence address: Silvia Kutscher, Institut fur Deutsche Sprache und Literatur, Universität Köln, Albertus-Magnus-Platz, 50923 Köln, Germany. E-mail: silvia.kutscher@uni-koeln.de.

2. In spoken German there is a second type of 'where' question containing the possession verb haben 'have', e.g. wo hast $d u X$ ? 'where do you have X?'. This is used rather frequently in colloquial speech, to inquire about the location of an (inanimate) entity known to be in possession, and under control, of the addressee. In an answer to such a question, a parallel expression involving haben can be used, e.g., mein Werkzeug habe ich im Keller 'I have/keep my tools in the cellar'. In the latter, no information about the position of the Figure is conveyed. Alternatively, the BLC can also be employed in an answer to such a question.

3. With certain prepositions, the dative is in opposition to the accusative, which is used to indicate motion.

4. Abbreviations used in the schematic representations and interlinear glosses are: ADV - adverbial; AUX — auxiliary; DAT — dative; DEM — demonstrative; ITR — intransitive; MOD.PTKL — modal particle; NEG — negation; NOM nominative; NP - noun phrase; P — preposition; PL — plural; POSS — possessive pronoun; PTKL - particle; PTCP.PERF — perfect participle; PRS — present tense; PST — past tense; SG — singular; SUBJUNCT — subjunctive; TR — transitive; V verb. In the interest of readability, glosses are kept to a minimum, e.g., case marking and gender is not glossed.

5. Since sein 'be' can take part in the BLC, we consider it a locative verb for the purpose of our paper, even though it functions as a copula as well.

6. In addition, the positional verb without a locative PP may be subject to semantic specialization or stereotypical interpretation. For example, in the case of sitzen with a human subject the interpretation is "be in jail', e.g., "Wo ist Peter" _ "Der sitzt" " "Where is Peter" _ "He's in jail",. An example of a stereotypical interpretation is der Schlüssel steckt 'the key is in the keyhole'.

7. The existential construction is distinct from the presentational construction in German. It consists of an expletive pronoun and the invariable $3 \mathrm{rd}$ person singular of the verb geben 'give'. Typically a locative expression is included, e.g., Es gibt hier viele Bücher 
'There are lots of books here'. Negative existential expressions are formed with the negative indefinite article, e.g., Es gibt hier keine Bücher 'There are no books here'.

8. In this respect German differs strikingly from the closely related Germanic language Dutch, where zitten 'sit' is one of the positionals used with inanimate Figures.

9. Marginally, schweben can also be used when the Ground is a liquid; see Section 3.9.

10. For example, stehen is conventionalized with celestial bodies, e.g., Die Sonne steht am Himmel 'the sun is in the sky' (cf. also Serra Borneto 1996: 472).

11. They both contrast with the positional lehnen 'lean' which in addition to the semantic component 'support from below' contains the component of 'support from the side' (see Section 3.5).

12. In fact, one speaker directly referred to this non-canonical position as 'standing', although emphasizing that in German the use of the positional stehen is not appropriate for referring to leaves: Es sieht fast so aus, (...) als ob es stehen würde, aber kann man nicht sagen 'It almost looks (...) as if it was standing but one cannot say that'.

13. For reasons of space, 'stick(ITR)' rather than the more appropriate 'be in tight fit' is used in glosses of the examples. It is important to remember though that stecken unlike English stick does not extend to configurations of adherence by means of a sticky substance.

14. The German Dictionary edited by W. and J. Grimm (DWb) gives 'seize (with claws)' as the original meaning of klemmen and cites the following passage from a middle high German epic by Wernher vom Niederrhein, which deals with an eagle that throws one of its chicks out of the nest.

(i) sô clemmithe iz mit sînem vuoze then seized he it with his foot

'Then he (the eagle) seized it (the chick) with his claw.'

(DWb vol. 11, col. 1139,5)

15. Semantically haken 'get caught' (lit. 'get hooked') refers to the attachment of a Figure to a Ground by means of one or several hooks, but may be metaphorically extended to rough surfaces,. Formally, the verb haken is not a positional verb in the sense used in this paper since it does not take a Ground PP obligatorily.

\section{References}

Berthele, Raphael (2004a). The typology of motion and posture verbs. A variationist account. In Dialectology Meets Typology. Dialect Grammar from a Cross-Linguistic Perspective, 93-126. Berlin and New York: Mouton de Gruyter.

- (2004b). Variation im Bereich der Positionsverben und Ortsadverbiale. Alemannisch im Vergleich mit der Standardsprache und mit benachbarten romanischen Sprachen. In Alemannisch im Sprachvergleich, Zeitschrift für Dialektologie und Linguistik, Beihefte 129, Elvira Glaser, Peter Ott, and Rudolf Schwarzenbach (eds.), 31-50. Stuttgart: Steiner.

Coseriu, Eugenio (1968). Les structures lexématiques. In Probleme der Semantik, Beihefte der Zeitschrift für Französische Sprache und Literatur, Theodor Elwert (ed.), 3-16. Wiesbaden: Franz Steiner.

Drosdowski, Günther (ed.) (1983). Duden: Deutsches Universalwörterbuch. Mannheim: Dudenverlag.

Fagan, Sarah M. B. (1991). The semantics of the positional predicates liegen/legen, sitzen/ setzen, and stehen/stellen. Unterrichtspraxis 24(2), 136-145. 


\section{S. Kutscher and E. Schultze-Berndt}

Gerling, Martin and Orthen, Norbert (1979). Deutsche Zustands- und Bewegungsverben. Eine Untersuchung zu ihrer semantischen Struktur und Valenz. Tübingen: Narr.

Grimm, Jacob and Grimm, Wilhelm (1854-1960). Deutsches Wörterbuch von Jacob und Wilhelm Grimm. Edited by Arbeitsstelle des Deutschen Wörterbuches zu Berlin. Leipzig: Hirzel.

Kaufmann, Ingrid (1995). Konzeptuelle Grundlagen semantischer Dekompositionsstrukturen: Die Kombinatorik lokaler Verben und prädikativer Komplemente. Linguistische Arbeiten 335. Tübingen: Niemeyer.

Kita, Sotaro (2007). Figure-Ground indeterminacy in descriptions of spatial relations: a construction grammar account. In Crosslinguistic Perspectives on Argument Structure: Implications for Learnability, Melissa Bowerman and Penelope Brown (eds.), 89-109. Mahwah, NJ: Erlbaum.

Kotschi, Thomas (1974). Probleme der Beschreibung lexikalischer Strukturen. Untersuchungen am Beispiel des französischen Verbs. Tübingen: Niemeyer.

Lemmens, Maarten (2002). The semantic network of Dutch posture verbs. In The Linguistics of Sitting, Standing and Lying, John Newman (ed.), 103-139. Amsterdam: Benjamins.

Levin, Beth (1993). English Verb Classes and Alternations. A Preliminary Investigation. Chicago: University of Chicago Press.

Levinson, Stephen C. (2000). Presumptive Meanings. The Theory of Generalised Conversational Implicatures. Cambridge, MA: MIT Press.

Maienborn, Claudia (1990). Position und Bewegung: Zur Semantik lokaler Verben. IWBS Report 138. Stuttgart: IBM Deutschland.

- (1991). Bewegungs- und Positionsverben: Zur Fakultativität des lokalen Arguments. In Betriebslinguistik und Linguistikbetrieb: Akten des 24. Linguistischen Kolloquiums, Universität Bremen, 4.-6. September 1989, Vol. II, Eberhard Klein, Francoise P. Duteil, and Karl Heinz Wagner (eds.), 95-106. Tübingen: Niemeyer.

Serra Borneto, Carlo (1996). Liegen und stehen in German: a study in horizontality and verticality. In Cognitive Linguistics in the Redwoods: The Expansion of a New Paradigm, CLR 6, Eugene H. Casad (ed.), 459-506. Berlin and New York: Mouton de Gruyter.

Wahrig, Gerhard (1975). Deutsches Wörterbuch: Mit einem "Lexikon der deutschen Sprachlehre". Gütersloh: Bertelsmann.

Wunderlich, Dieter and Kaufmann, Ingrid (1990). Lokale Verben und Präpositionen: Semantische und konzeptuelle Aspekte. In Sprache und Wissen: Studien zur Kognitiven Linguistik, Sascha W. Felix, Siegfried Kanngiesser, and Gert Rickheit (eds.), 223-252. Opladen: Westdeutscher Verlag. 